\title{
SUSTAINABLE URBAN SPACE EXPANSION IN CENTRAL YUNNAN (CHINA): REGIONAL URBAN INTEGRATION
}

\author{
ZIJIANG YANG, XIONG HE, KUN ZHANG \& JUN ZHANG \\ School of Architecture and Planning, Yunnan University, China.
}

\begin{abstract}
The topic of sustainable development of cities is a hotspot and focus of urban research. The expansion of urban space is the most intuitive embodiment of sustainable urban development. To explore the current status and trends of urban space expansion in Kunming and Yuxi, the central cities of Yunnan Province in China, this study uses land use data from 2000 to 2015 to analyze, the spatial shape and expansion trend of Kunming and Yuxi using the compactness index and the Lacunarity index. Results show that the most obvious urban space expansion in 2000 to 2005 is characterized by the expansion of the urban center circle and the independence of each central space. Urban space expansion from 2005 to 2010 is characterized by the relative expansion of the city and integration of the built-up area. The expansion of urban space from 2010 to 2015 is distinct and shows a trend of continuous expansion. Finally, preliminary conclusions are drawn indicating that the urban space in the selected case study area is sustainable. The sustainable development model of urban space in China's central Yunnan is represented by regional urban integration.

Keywords: integration, Lacunarity, spatial expansion, sustainability.
\end{abstract}

\section{INTRODUCTION}

As the level of urbanization increases, many adjacent cities gradually connect in geographical space. The degree of cooperation between cities has significantly improved, showing the development trend of urban regional integration [1,2]. Administrative obstacles and realistic conditions constrain the choice of urban construction land and spatial construction, which also leads to the increasingly obvious conflict between interest distribution and spatial development [3]. In the face of such a dilemma, scholars began to explore the sustainability of urban spatial expansion and summarized the sustainable development model of the city $[4,5]$. At present, the exploration of sustainable cities mainly includes the construction of a sustainable urban development framework [6] and indicators to evaluate sustainable cities [7, 8].

From the thorny issues concerning social and spatial development today, the concept of sustainable urban spatial structure and model is explained. And pointed out that the urban space expansion formula needs to be changed. The extensive material and economical extensive and disorderly mode of dissemination should be abolished in the past and a sustainable urban spatial expansion policy should be created $[9,10]$. Sustainable urban land use is a primary concern in the study of sustainable urban space development because urban land use change is the most direct factor leading to urban spatial expansion [11]. Relative to urban road traffic structures and the economic reality of residents, urban land use change is a more effective measure with which to study the sustainable development of a city at the macro level.

Some scholars have proposed that effective urban space management measures, such as the formulation of land development policies and timely government intervention [14], are critical for urban spatial expansion and sustainability [12, 13]. Urban sustainable development scholars in the United States developed the theory of smart growth based on characteristics of the undesirable phenomena defined as urban sprawl [15]. And the 
exploration of urban sustainable development based on the expansion of urban space will bring us a new direction. At present, the main emphasis in developed countries such as Europe and the United States is on the sustainability of urban space development through community walking possibilities, spatial compactness, mixed use, and renovation of buildings [16]. In recent years, researchers have begun to focus on developing countries with high population density in East Asia and Southeast Asia [17, 18]. Among them, the expansion of urban space for India and China is the best [19]. In these studies, urban spatial development is reflected mainly through land changes in urban construction. Previous Chinese remote sensing studies on urban spatial development distinguished compact and decentralized urban forms of urban spatial expansion [20]. At present, research on urban spatial expansion in China has gradually shifted to the study of land use change [21, 22]. There were considerable results conducted by using the measures including the landscape expansion index and area-weighted mean distance index to explore the space expansion of Chinese cities.

From the perspective of urban integration, the main research includes the dynamic mechanism of urban integration and the spatial organization model and its organizational structure $[15,23,24]$. The boom of urban movements in the 1970s prompted scholars to pay attention to dynamic changes in the spatial structure of urban integration. In the 1980s, the development momentum of urban suburbs emerged and research hotspots shifted to the study of multi-core relative aggregation evolution in urban space [25]. For developing countries, the main focus of urban spatial integration is on urban-rural mixed and extended metropolitan areas [26]. At present, most scholars have begun to study urban spatial expansion and integration development characteristics of China [27]. Although urbanization has increased significantly over the past 20 years, overall progress and level are still low [28].

The speed, level [29], mode [30], and socioenvironmental impacts [31] of urban spatial expansion have been studied in detail around the world. However, there is no detailed explanation for factors such as the shape, scale, pattern, and characteristics of urban spatial expansion. The problems that need to be solved in the central cities of Yunnan Province are not caused only by rapid urbanization of those cities, but also by the development of the region and other aspects. Therefore, it is necessary to think about the expansion of urban space from a higher perspective of sustainable urban development [32, 33]. Urban sustainable development is closely related to the city's road traffic structure, service facilities, residents' social and economic realities, and building layouts. However, this study only explores the sustainable development model of the city from the perspective of urban space expansion. Therefore, a compactness index and a Lacunarity index are introduced. The Lacunarity index is used extensively to describe the spatial pattern of urban land use in macro and micro in China's case studies, and shows the superior suitability to the complexity of urban land spatial framework $[34,35]$.

\section{RESEARCH AREA AND DATA PROCESSING}

\subsection{Study area selection}

The central cities of Yunnan include Kunming and Yuxi (see Fig. 1). They are typical cities in southwestern China, with relatively special economic and geographical locations, and are typical plateau mountain cities. The two cities have in-depth cooperation in space, economy, and industry, and have the prerequisites for urban integration. These two cities are the regions with the highest level of urbanization in Yunnan. With the strategic policies of 'Yunnan 


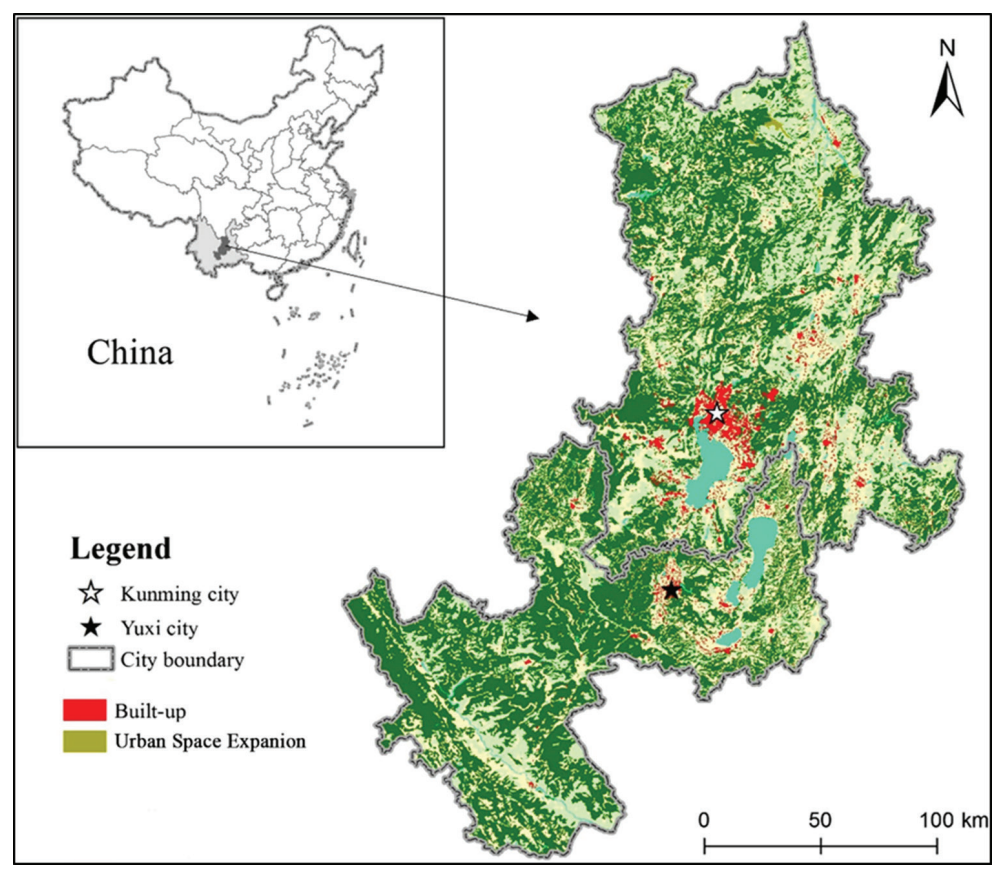

Figure 1: Study area and urban space expansion map.

Central Urban Agglomeration' and 'Integration of Kunming and Yuxi', the two cities have facilitated in-depth cooperation in space, economy, industry, transportation and culture. Studying the spatial expansion of Yunnan's central cities is not only an evaluation of western China's development strategy, but can also create a healthy and sustainable development model for Yunnan.

The construction of Kunming and Yuxi cities has accelerated due to urgent requirements for regional development spurred on by land use. This has also caused dramatic changes in the land use pattern in the region and triggered a series of ecological problems. Therefore, to address these various issues, it is first necessary to investigate the spatial expansion of the cities in central Yunnan, including Kunming and Yuxi.

Further, with the steady development of China's 'One Belt, One Road' strategy, the urban development of Kunming and Yuxi is reflective of new national development goals and requirements. Kunming and Yuxi clearly exhibit the natural environment characteristics of the plateau-lakeside landscape city and the sustainable development potential of typical western China cities in both the 'Urban Immediate Planning (2016-2020)' and 'National Land Space Planning (2018-2035)' national policy plans. Therefore, by studying the sustainable development model of Yunnan's central cities, pertinent information for other provinces and their developing cities may emerge.

\subsection{Data acquisition and processing}

The data used in this study is remote sensing image data from 2000 to 2015. This paper uses TM (Thematic Mapper), ETM (Enhanced Thematic Mapper), OLI-TIRS (Operational Land 


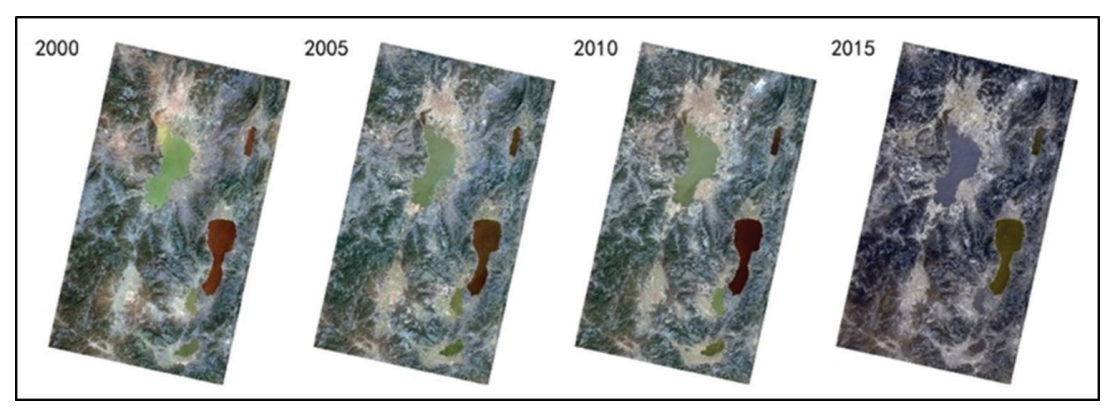

Figure 2: Post-processed remote sensing imagery of the four periods of the study area.

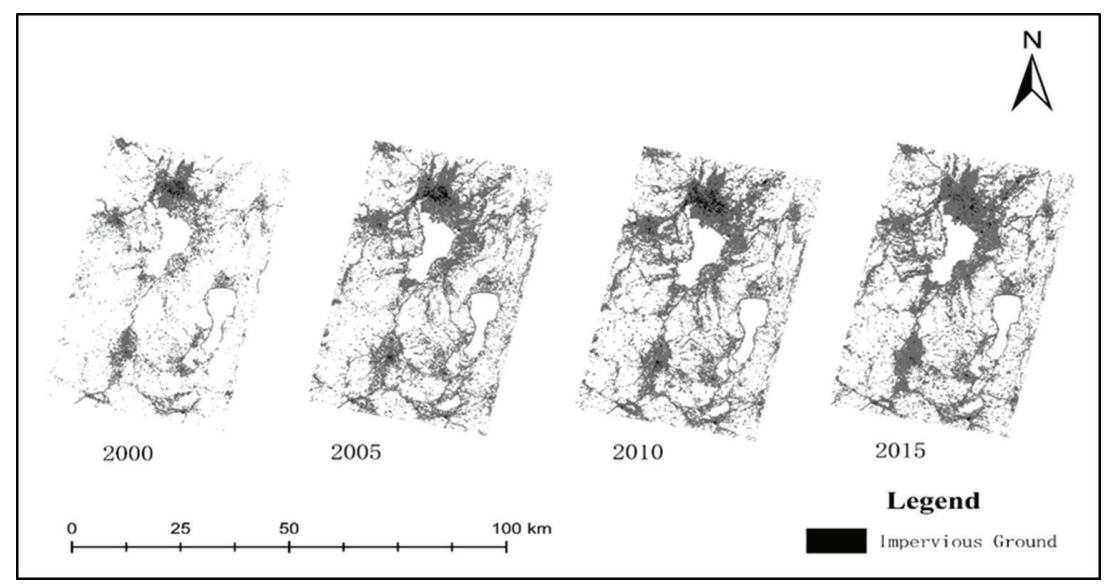

Figure 3: Classification of processed remote sensing images the study area across four time periods.

Imager-Thermal Infrared Sensor) images taken by Landsat satellites in 2000, 2005, 2010 and 2015.

The Landsat images used in this study are from multiple time periods and multiple sensors. In order to match their spatial resolution, the four remote sensing images of the study area were resampled by the GIS (Geographic Information System). It is the images that were unified into a 30m spatial resolution image for geometric pre-processing and image fusion. The image was then cropped by the boundary vector diagram to create the multi-band, cropped remote sensing image map of the study area. Figure 2 shows the final results of the image processing.

Using ENVI (The Environment for Visualizing Images), the land use types in the study area were divided into built and non-built land (see Fig. 3). Based on a supervised classification, the ROI (Region of Interest) test interpreted the longitude of the four remote sensing images at $88.45 \%, 92.27 \%, 90.00 \%, 98.57 \%$ (more than 85\%), respectively, with Kappa values of 0.7963 , $0.7953,0.7426,0.9566$ (more than 0.75 ). These values are within research requirements.

\section{RESEARCH METHODS}

In order to explore the urban spatial expansion characteristics of Kunming and Yuxi in central Yunnan, the compactness index and the Lacunarity index are used to explore the urban spatial pattern and evolution rules. Compactness and Lacunarity indices are commonly used in 
morphological pattern studies. The compactness index reflects the relationship between urban area and urban perimeter. When the city shape is close to a circle, the compactness is close to 1 .

When multiple urbanized areas are docked together, spatial heterogeneity is significantly enhanced until multiple urbanized areas are integrated and the urban space tends to be homogeneous. The Lacunarity index can quantitatively measure the heterogeneity of urban spatial expansion.

Compactness index:

$$
C=2 \sqrt{\pi A} \div P
$$

In the formula, $\mathrm{C}$ refers to the compactness of the city, $\mathrm{A}$ refers to the urban area, and $\mathrm{P}$ refers to the perimeter of the city outline. The compactness index ranges between 0 and 1 ; the larger the value, the higher the city's shape compactness. Conversely, a lower value means the compactness of a city's shape is lower.

Lacunarity index:

The Lacunarity index includes a global Lacunarity index and a local Lacunarity index. The global Lacunarity index is used to describe the measurement of the overall characteristics of urban space land and to study the heterogeneity between urban land use by scale. The local Lacunarity degree index is used to describe the extended features of urban space land and the spatial pattern of land use.

Global Lacunarity index:

$$
\Lambda(r)=\frac{\sum_{M} M^{2} Q(M, r)}{\left[\sum_{M} M Q(M, r)\right]^{2}}
$$

Where $\Lambda(r)$ is the global Lacunarity index; $r$ is the sampling grid size; $\mathrm{M}$ is the number of objects occupied by the object under the $r$ sampling square; and, $Q(M, r)$ is the probability distribution of the object under the sampling grid.

Local Lacunarity index:

$$
L \Lambda(r)=\frac{\sum_{M_{w}} M_{w}^{2} Q\left(M_{w}, r\right)}{\left[\sum_{M_{w}} M_{w} Q\left(M_{w}, r\right)\right]^{2}}
$$

Where $L \Lambda(r)$ is the local clearance index and $M w$ is the local area $(w \times w)$. The inner length is the number of urban lands in the $r$ sampling grid. The remaining variables are as shown in eqn. (2).

The model construction and detailed calculation of the Lacunarity index can refer to the Research on Urban Expansion Methods Based on Lacunarity Index proposed by He in 2019 [35].

\section{ASSESSMENT}

\subsection{Urban space compactness}

Using ArcGIS, more accurate urban perimeter and area data are obtained by extracting the boundary of the built-up area of Kunming and Yuxi and manually removing the finely-shaped dotted areas that strongly interfere with the side length of the city. Thus, the spatial compactness of the urban built-up area was calculated. 
It can be seen from Table 1 that the compactness of the built-up area of the study area generally shows a slight decline and then a gentle trend. This indicates that the land use in the study area is not enough, there is a small degree of space utilization, the form is relatively complex, and there is a clear expansion of urban space.

From 2000 to 2005, the study area's urban space was in a state of rapid expansion. There are both extended modes of the circle and areas that extend along the road radiation. Therefore, the compactness of urban space has been reduced. From 2005 to 2010, urban space still maintained a circle expansion model. In the previous stage, the extended area around the road was slightly filled and the compactness index increased slightly. From 2010 to 2015, urban space showed a small amount of point spread and road radiation expansion and the compactness index resumed its decline.

\subsection{Urban space Lacunarity}

The global Lacunarity degree index change logarithm curve is generated by the global Lacunarity index calculation (where the sampling grid scale varies between 2 and 100 units), as shown below in Fig. 4:

Under the same sampling grid, the global Lacunarity degree index in 2000 was significantly higher than in 2005, 2010 and 2015. This is because there was significantly less area of urban

Table 1: Table of urban area, perimeter length, and compactness index for the study area.

\begin{tabular}{cccc}
\hline Year & $\begin{array}{c}\text { Urban area } \\
\text { (hectare) }\end{array}$ & Perimeter $(\mathbf{k m})$ & Compactness \\
\hline 2000 & 29711.968 & 5938.124 & 0.103 \\
2005 & 60636.981 & 12692.43 & 0.069 \\
2010 & 82155.042 & 14154.41 & 0.072 \\
2015 & 84932.796 & 16118.01 & 0.064 \\
\hline
\end{tabular}

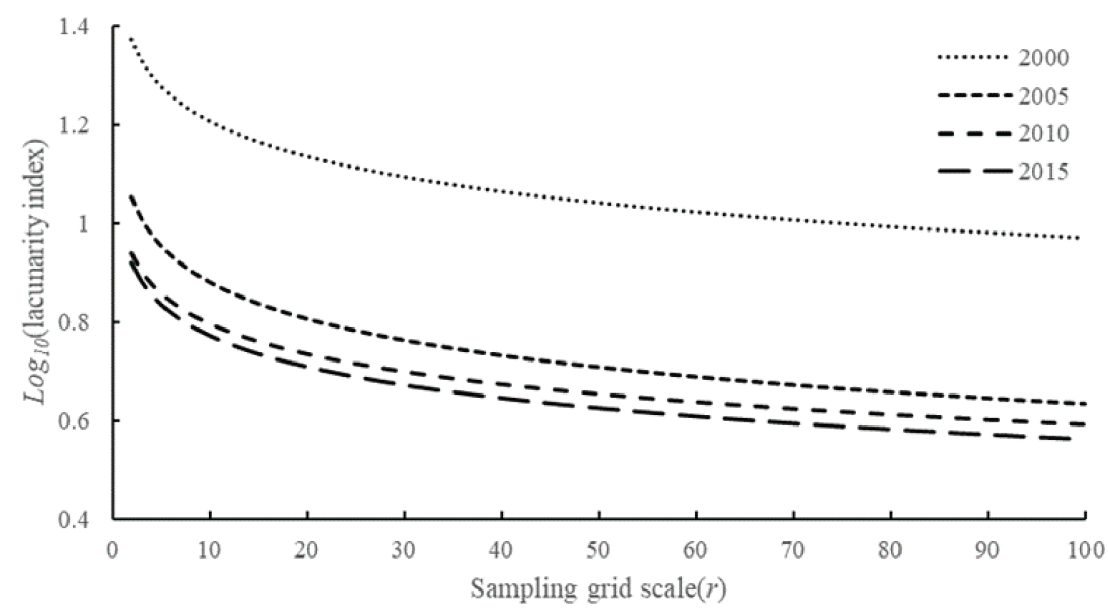

Figure 4: Graph of global Lacunarity index for different time periods and different sampling grids. 
built environment in 2000 compared to other three periods. In 2000, the urban built environment was the least concentrated. As a result, the global Lacunarity index was the highest in 2000. Under the same sampling grid, the urban construction land area in the three periods of 2005, 2010 and 2015 increased along with the degree of aggregation. This indicates that a clear explanation of urban space expansion in the study, as well as the general trend of urban space expansion. The change in the global Lacunarity index is noticeably more dramatic for the first five years than over the remaining ten years. Overall, based on the same sampling grid of the global Lacunarity index, the urban built environment clearly increased over the span of 15 years. Between 2000 and 2005, urban space expansion was most evident.

Under different sampling grids for the same year, the global Lacunarity degree index decreases as the sampling grid scale increases. All four years show the same fast-then-slow downward trend of the Lacunarity index. The reason for this is that there is a 'decentralization' in the expansion of urban space in the study area. The 'decentralized' urban space expansion will inevitably lead to the multi-polar expansion of the city, which will lead to the rapid growth of the urban built environment. And it can be seen that the urban construction areas of Kunming and Yuxi are intermingling. On different spatial scales, the heterogeneity of urban spatial expansion is weakening the overall expansion mode of regional integration.

By comparing the results for the four years with the same sampling grid and different sampling grids, the spatial expansion of the urban area of the study area can be preliminarily analyzed. It is better to analyze the sustainable mode of urban expansion through the heterogeneity of urban space. Furthermore, the expansion of urban space in central Yunnan will inevitably be accompanied by regional urban integration.

Urban built environment for the four years is calculated by the local Lacunarity index. The side length of the local area is set to 30 units to generate a partial Lacunarity degree index change map for each year (Fig. 5). By comparing the local Lacunarity degree index maps of the four periods, it can be seen that the local Lacunarity degree index distribution and the local Lacunarity degree index in 2000 is significantly smaller than those of the other three periods. The reason is the same as that of the global Lacunarity index. In 2000, the area of the urban built environment was smaller than that of the other three time periods. The local interstitial index exhibits a divergent pattern in spatial distribution. The low-value areas of the local interstitial index are mainly distributed in the relative isolation of Kunming and Yuxi city centres. The regional Lacunarity index of the area gradually increases from the center of Kunming and Yuxi to the periphery, and the spatial difference is more significant. Secondly, judging from the pattern in 2000, the urban spatial expansion in the region mainly grows around the two city centers and has a distinct edge expansion feature.

The distribution of lower value of the local Lacunarity index in 2005 was significantly larger than that in 2000. In addition to the low-value areas gathered in Kunming and Yuxi city centres, local low-value area connections have also occurred at the junctions between Kunming and Yuxi. In particular, there are more areas with low local clearance in the east bank of Dianchi Lake. It can be seen from this that the urban space expansion in 2005 is mainly due to the growth of the Dianchi Lake corridor between Kunming and Yuxi. Moreover, the corridor of low-value local Lacunarity index highlights the growing connection between the two cities and shows the link between integration and urban development.

Comparing the partial Lacunarity degree index maps of 2010 and 2015, the low-value areas continue to increase across these two years. This also reflects the furthered expansion of urban space. However, the increase in the low-value areas around the outer city areas of Kunming and Yuxi is not obvious. Rather, the corridor around the east bank of Dianchi Lake linking Kunming and Yuxi continues to expand, forming a channel of low-value local 

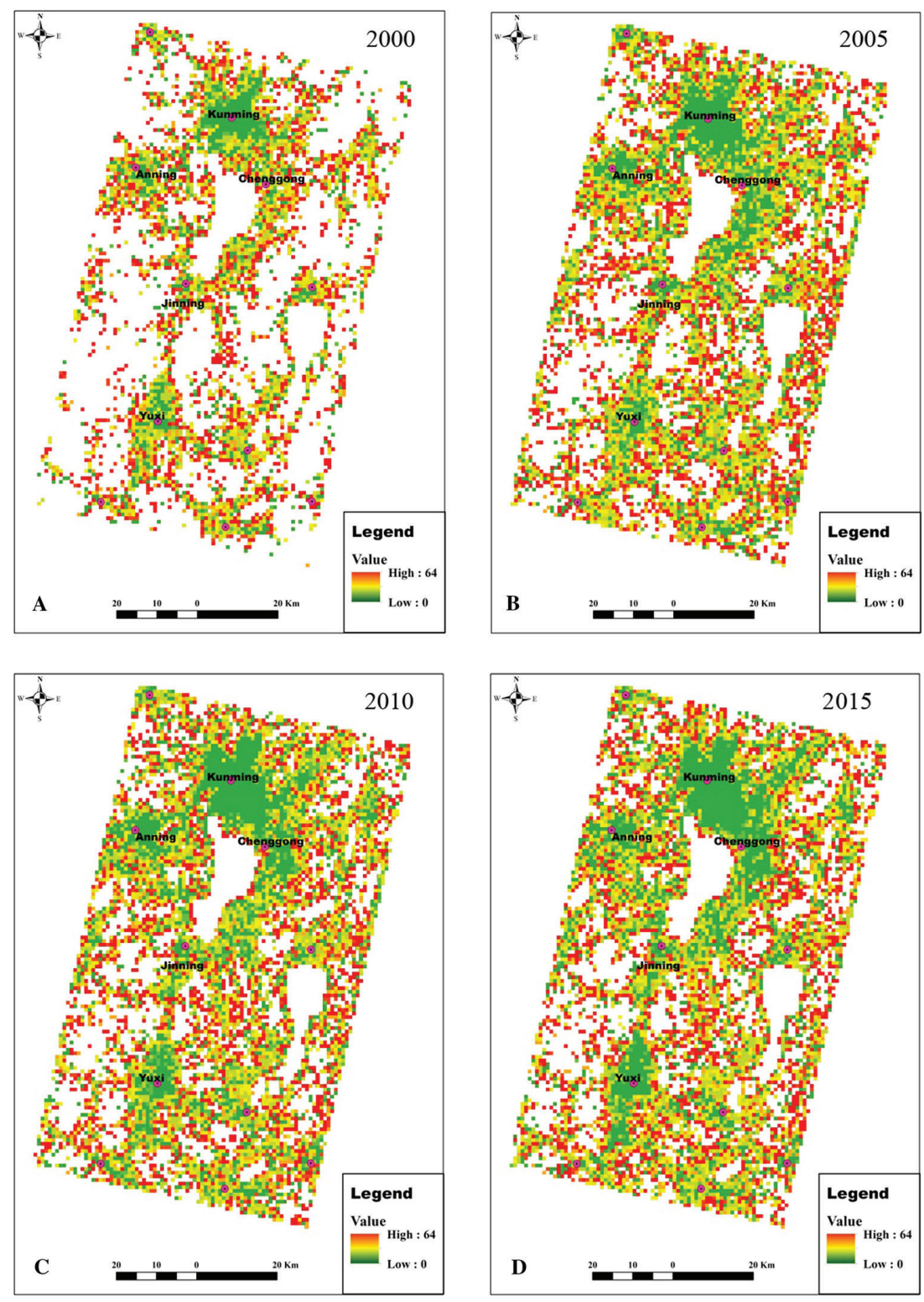

Figure 5: Local Lacunarity index from 2000 to 2015.

Lacunarity index. This repeated growth pattern further indicates the direction and trend of the region's urban space expansion.

Comparing the regional Lacunarity degree index maps of the four periods in the study area, the urban spatial expansion direction and trend of the cities in central Yunnan can be analyzed. The first two periods of growth were mainly due to the outward expansion of Kunming and Yuxi city centers, which showed a trend of expansion at the edges. The latter two periods are mainly on the extension along the east bank of Dianchi Lake as well as expanded intracity connections. The two cities are expanding in relation to each other and both continue to 
increase over the time period studied. From the local interstitial index of the four periods, it can be concluded that the basic pattern of urban spatial expansion in Kunming and Yuxi has expanded from a relatively isolated space to an urban, integrated space over 15 years. This demonstrates the sustained growth in urban spatial expansion and highlights the gradual integration of urban space. At the same time, there is an evident but subtle decentralization of urban space across the region.

The experimental data show a clear urban expansion of Kunming and Yuxi cities. It can be seen from the low compactness index that the urban spatial form is complex and that land use changes rapidly. Through the change of the index, it can be concluded that the urban space expansion is most evident from 2000 to 2005 . The main manifestation is the expansion of the circle and the expansion along the road, mainly due to the rapid changes in land use. A large increase in built-area around the city center of Kunming and Yuxi led to a significant decline in the compactness index. From 2005 to 2015, the change in the index is not as evident, because the main area of urban expansion is no longer around the city center. Instead, there is large amount of urban built-area on the east bank of Dianchi Lake connecting the two cities.

From the Lacunarity degree index, we can see changes in the trend of urban spatial expansion. The global Lacunarity index indicates that in urban spatial expansion, the city appears as a 'decentralized' expansion pattern. The 'decentralization' of cities has led to the expansion of urban expansion with multi-polarization, especially in 2000-2005. As the 'decentralized' expansion pattern weakens, the built-up areas of the two cities merge. As urban development tends to develop and integrate in phases, so too does the weakening of the spatial heterogeneity of cities. This is reflected by the local Lacunarity degree index maps for Kunming and Yuxi. In 2000-2005, the spatial expansion of the two cities spread around the urban center to the periphery, presenting a relatively isolated spatial expansion trend. By 2005-2010, however, the built-up areas of the two cities have already merged on the east bank of Dianchi Lake. The expansion trend is manifested as a relative expansion. In 2010-2015, the spatial expansion of the two cities has become a very obvious trend in urban space expansion.

From 2000 to 2015, urban spatial expansion continued across Yunnan's central cities, Kunming and Yuxi. However, there were noticeable changes to the form, pattern, and trend of this urban space expansion. From the perspective of space and scale, the spatial expansion of the future city appears to be regional urban integration under sustainable conditions.

\section{DISCUSSION}

Sustainable urban development is a macro issue, as well as providing guidance to implementation on the ground. Urban researchers have continuously explored how to ensure the healthy and sustainable development of cities. This study is based on urban space expansion as an entry point, based on data on land use change in Kunming and Yuxi over 15 years. The spatial expansion of the city is analyzed in detail using the compactness and the Lacunarity index. The analysis results show that the urban space expansion in the study area is sustainable. In the 15 years of urban space expansion, the city experienced central expansion, peripheral expansion, phase expansion and contiguous expansion. Eventually, this expansion has tended towards urban regional integration. It is a new exploration paradigm to explain the sustainable development of cities through the expansion of urban space. It is more objective than the economic, population and other factors to explore urban sustainability. However, there are still some shortcomings in this study, as detailed below.

First, sustainable urban development is a concept that is worthy of long-term exploration. In this study, 15 years of land use data and compactness index and Lacunarity index were used. In terms of data, urban changes require long-term, continuous data for observation. 
This study is also slightly thin on the data support and needs to be supplemented. In terms of methodology utilized, the compactness index only expresses the relationship between area and perimeter. The Lacunarity index is dependent on observation scale, and the research method requires further improvement. In terms of a potential next stage of the study, more urban data will be obtained and the original methods will be improved to provide a more detailed analysis of the sustainability of urban space expansion.

Second, this study analyzes the sustainability of urban spatial expansion in the past 15 years and concludes that urban expansion is sustainable. And it is concluded that the future sustainable urban expansion trend will be regional urban integration. But there is a lack of analogy evolution of urban space expansion over the next decade or more. In the next stage of the study, it is hoped to simulate the expansion of the future urban space. This can support the conclusions of this study from another aspect.

Third, the sustainable development of the city is also clearly linked to the type of buildings in the middle of the city, the spatial layout of the buildings, and the economic activities within the city. These factors will have an impact on the development of the city. In the follow-on study, the authors will further explore the complex parameters of urban activities (urban services, urban environment, etc.) and the correlation between indicators and sustainable urban development.

Sustainable development of cities is bound to be accompanied by changes in land use. Land use is also one of the core issues of urban space expansion. From the expansion of urban space to illustrate the sustainability of the city, this is a good inspiration and reference for the future study of urban sustainability. Although there are some shortcomings in this study, this is a positive exploration of urban sustainable development and urban spatial expansion.

\section{CONCLUSION}

The urban spatial expansion of Kunming and Yuxi was analysed using both the compactness index and the Lacunarity index. The results show from 2000 to 2015, the 'decentralization' of urban built-up areas led to the existence of significant urban spatial expansion in the study area. In the first five years, the urban space expansion in the study area was relatively isolated, mainly expanded around the city centers. The middle five years showed areas of expansion concentrated mainly near the east bank of Dianchi Lake. The emergence of this lake corridor began the convergence of the two cities' built-up areas. In the last five years, the trend of urban spatial expansion continues along a similar path. Overall, urban space expansion shows sustained growth and, according to this analysis of remotely-sensed imagery, sustainable urban spatial expansion will certainly be regional urban integration.

\section{REFERENCES}

[1] Sun, P.J., Xiu, C. L. Progress in Research on Urban Spatial Expansion of China. Areal Research and Development 2014, 33, 46-52. [CrossRef]

[2] Rafiee, R., Mahiny, A.S., Khorasani, N., Darvishsefat, A.A., Danekar, A. Simulating urban growth in Mashad City, Iran through the SLEUTH model (UGM). Cities 2009, 26, 19-26. [CrossRef]

[3] Cui, G.H. Urban Issue as the Regional Issue-The Establishment and Development of the Regional View of Urban Planning in China. Urban Planning Forum 2010, 24-28. [CrossRef]

[4] Wiryananda, N., Hasibuan, H.S, Madiasworo, T. Study of urban spatial utilization on socio-cultural and environment based on sustainability index (study in Denpasar city) 
$[C] / / I O P$ Conference Series: Earth and Environmental Science. IOP Publishing, 2018, 126(1), p. 012136. [CrossRef]

[5] Muminovic M. Place identity and sustainable urban regeneration: Public space in Canberra City Centre[J]. Urban Regeneration \& Sustainability, 2016, p. 374. [CrossRef]

[6] Li, Y., Beeton, R.J.S, Sigler, T., et al. Modelling the transition toward urban sustainability: A case study of the industrial city of Jinchang, China[J]. Journal of Cleaner Production, 2016, 134, pp. 22-30. [CrossRef]

[7] Peng, J., Du, Y., Ma, J., et al. Sustainability evaluation of natural capital utilization based on 3DEF model: A case study in Beijing City, China[J]. Ecological Indicators, 2015, 58, pp. 254-266. [CrossRef]

[8] Reis, I.F.C, Ferreira, F.A.F., Meidutė-Kavaliauskienè, I., et al. An evaluation thermometer for assessing city sustainability and livability[J]. Sustainable Cities and Society, 2019, 47, p. 101449. [CrossRef]

[9] Shen, J., Wong, K.Y., Feng, Z.Q. State sponsored and spontaneous urbanization in the Pearl River Delta of south China,1980-1998. Urban Geography 2002, 23, pp. 674-694. [CrossRef]

[10] Shen, J., Feng, Z.Q., Wong, K.Y. Dual- track urbanization in a transitional economy: The case of Pearl River Delta insouth China. Habitat International 2006, 30, pp. 690-705. [CrossRef]

[11] Tan, M.H., Li, X.B., Lu, C.H. Urban land expansion and arable land loss of the major cities in China in the 1990s. China Ser. D-Earth Sci. 2005, 48, pp. 1492-1500. [Springer]

[12] Zhang, Z.H., Zhang, P., Wang, X.Z., Yu. K.H. A Study on the Research Progress of Sustainable Urban Space in Foreign Countries. Urban planning Forum 2009, pp. 99-107. [CrossRef]

[13] Shen, J.F. Estimating urbanization levels in Chinese provinces in 1982-2000. International Statistical Review 2006, 74, pp. 89-107. [CrossRef]

[14] Nijkamp, P., Rodenburg, C.A., Wagtendonk, A.J. Success factors for sustainable urban brownfield development - A comparative case study approach to polluted sites. Ecological Economics 2002, 40, pp. 235-252. [CrossRef]

[15] Duranton, G., Puga, D. Diversity and specialization in cities: Why, where and when does it matter. Urban Studies 2000, 37, pp. 533-555. [CrossRef]

[16] Kontokosta, C. E. Tall buildings and Urban expansion: Tracing the evolution of zoning in the United States[J]. Leadership and Management in Engineering, 2013, 13(3), pp. 190-198. [CrossRef ]

[17] Lambin, E.F. \& Geist, H. Land-use and land-cover change: Local processes and global impacts. Springer, Berlin, Heidelberg, 2006, pp. 25-26. [CrossRef]

[18] Seto, K.C., Woodcock, C.E., Song, C., Huang, X., Lu, J., Kaufmann, R.K. Monitoring land-use change in the Pearl River Delta using Landsat TM. International Journal Remote Sensing 2002, 23, pp. 1985-2004. [CrossRef]

[19] Seto, K.C., Shepherd, J.M. Global urban land-use trends and climate impacts. Current Opinion in Environmental Sustainability 2009, 1, pp. 89-95. [CrossRef]

[20] Schneider, A., Woodcock, C.E. Compact, dispersed, frag-mented, extensive? A comparison of urban growth in twenty-five global cities using remotely sensed data, pat-tern metrics and census information. Urban Studies 2008, 45, pp. 659-692. [CrossRef]

[21] Liu, K., Wang, J., Tang, P. Sprawling Urban form and expanding living space: A study on the relationship of Residential Space Development and Urban Built-up Area Expan- 
sion in Nanjing, China[J]. Journal of Asian Architecture and Building Engineering, 2015, 14(2), pp. 387-394. [CrossRef]

[22] Wang, C., Wang, Y., Wang, R., et al. Modeling and evaluating land-use/land-cover change for urban planning and sustainability: A case study of Dongying city, China[J]. Journal of Cleaner Production, 2018, 172, pp. 1529-1534. [CrossRef]

[23] Henderson, J.V. The sizes and types of cities. American Economics Review 1974, 64, pp. 640-656.

[24] Abdel-Rahman, H., Fujita, M. Product variety, Marshallian externalities and city sizes. Journal of Regional Science 1990, 30, pp. 165-183. [CrossRef]

[25] Wallis, A.D. Evolving structures and challenges of metropolitan region saugment. National Civic Review 1994, 83, pp. 40-53. [CrossRef]

[26] Gu, C.L. Study on urban agglomeration: Progress and prospects. Geographical Research 2011, 30, pp. 771-784. (In Chinese)

[27] Wang, Q., Xiu, C.L., Wei, Z. Analysis of the dynamic mechanism of urban spatial expansion: A case study of Shenyang City. Urban Problems 2014, pp. 29-35. [CrossRef]

[28] Ou, J., Liu, X., Li, X., et al. Quantifying spatiotemporal dynamics of urban growth modes in metropolitan cities of China: Beijing, Shanghai, Tianjin, and Guangzhou[J]. Journal of Urban Planning and Development 2016, 143(1), p. 04016023. [CrossRef]

[29] Wang, W. \& Wu, Z.Q. The measure and comparative research on spatial structure's integrated efficiency of Yangtze River Delta, Pearl River Delta and Beijing-Tianjin-Hebei Urban Agglomeration in China. Urban Development Studies 2013, 20, pp. 63-71. [CrossRef]

[30] Peng, Y.Y., Yang, R.X., Chen, P.P., Wang, R.X. Dynamic monitoring on significant geographical conditions of Zhengzhou-Kaifeng Integration Area. Remote Sensing Information 2014, pp. 41-46, 51. [CrossRef]

[31] Yi, G., Dong, S.H., \& Chen, H. Temporal evolution of spatial connection among cities of Dianzhong Urban Agglomeration from 2004 to 2013. Areal Research and Development 2015, pp. 65-70. [CrossRef]

[32] Wu, F., Li, L.H. \& Han, S.Y. Social sustainability and redevelopment of Urban Villages in China: A case study of Guangzhou. Sustainability 2018, 10, p. 2116. [CrossRef]

[33] Broekhoven, S.V. \& Vernay, A.L. Integrating functions for a Sustainable Urban System: A review of multifunctional land use and circular urban metabolism. Sustainability 2018, 10, p. 1875. [CrossRef]

[34] Wu, H., Sun, Y., Shi, W., et al. Examining the satellite-detected urban land use spatial patterns using multidimensional fractal dimension indices[J]. Remote sensing, 2013, 5(10), pp. 5152-5172. [CrossRef]

[35] He, X., Yang, Z., \& Zhang, K. Research on urban expansion methods based on lacunarity index[c]//Proceedings of the 2019 2nd International Conference on Geoinformatics and Data Analysis. ACM, 2019, pp. 93-98. [CrossRef] 